\title{
Low-dose vincristine in the treatment of corticosteroid-refractory idiopathic thrombocytopenic purpura (ITP) in non-splenectomized patients
}

\author{
F. Cervantes \\ M.D. \\ E. Montserrat \\ M.D. \\ C. ROZMAN \\ C. Diumenjo \\ E. FELIU \\ A. Grañena

\begin{abstract}
Postgraduate School of Haematology, 'Farreras Valenti', Hospital Clinico y Provincial,
\end{abstract} \\ Universidad de Barcelona, Spain
}

\begin{abstract}
Summary
Eight non-splenectomized patients with corticosteroidrefractory idiopathic thrombocytopenic purpura (ITP) were treated with low-dose vincristine $(1 \mathrm{mg} / \mathrm{week}$ up to a total dose of $4 \mathrm{mg}$ ). Complete remission was achieved in $\mathbf{2}$ cases and partial remission in 3 . Bleeding stopped in one patient who failed to remit. No statistical relationship was found between the response to vincristine and the duration of the disease or the corticosteroid-therapy. Side effects were only observed in one patient. By comparing these results with those reported in the literature, it can be inferred that low-dose vincristine may be useful in the management of corticosteroid-refractory ITP.
\end{abstract}

\section{Introduction}

The treatment of idiopathic thrombocytopenic purpura (ITP) is often difficult. Corticosteroids and/or splenectomy are successful in 70 to $90 \%$ of cases (Bouroncle and Doan, 1969; Harrington, Ahn and Gilibert, 1972; Ahn et al., 1974). When a beneficial response is not achieved, the disease is said to be refractory. Based on the concept that most cases are autoimmune in origin (Karpatkin, Strick and Suskind, 1972), immunosuppresive agents have been used, generally unsuccessfully (Finch et al., 1974). On the other hand, nonsteroidal immunosuppresive therapy is preferred when splenectomy and corticosteroids are contraindicated (Finch et al., 1974; Massimo et al., 1977; Tangun and Atamer, 1977). Cyclophosphamide and azathioprine have been widely used but trials have been performed with other drugs such as

Reprints from: Dr F. Cervantes, Postgraduate School of Haematology, Casanova, 143, Barcelona-36, Spain. methotrexate, chlorambucil, 6-mercaptopurnu, actinomycin C, L-asparaginase, thioguanine and Vinca alkaloids (Rozman, Rios and HernandezNieto, 1969; Ahn et al., 1974; Finch et al., 1974).

Vincristine is often useful in the treatment of refractory ITP (Harrington et al., 1972; Ahn et al., 1974; Burton et al., 1976; Ries, 1976; Tangun and Atamer, 1977; Rosse, 1978, Wautier et al., 1978), having the advantage of a faster action (Ahn et al., 1974). Because of this, its use has been recommended for producing a rise in the platelet count before splenectomy or to control bleeding (Burton et al., 1976). Vincristine appears to act by immunosuppression of the macrophages; and stimulation of platelet production by the bone marrow (Robertson and McCarthy, 1969; Robertson, Crozier and Woodend, 1972; Sultan et al., 1971). Dosages generally used are often associated with toxic side effects (Ahn et al., 1974; Burton et al., 1976).

In the present report, the results of low-dose vincristine therapy in 8 non-splenectomized patients with corticosteroid-refractory ITP are described.

\section{Material and methods}

Patients. Seven females and one male were studied, with a mean age of 30.6 years (range 17-48). The pertinent clinical data, duration of disease and corticosteroid therapy are summarized in Table 1. All patients had been unsuccessfully treated with corticosteroids before the institution of vincristine therapy.

Diagnostic criteria. ITP was diagnosed on the basis of history, clinical data and examination of peripheral blood and marrow smears. Diagnostic 
TABLE 1. Clinical and haematological data from the patients

\begin{tabular}{|c|c|c|c|c|c|c|c|c|}
\hline Case & Age & Sex & $\begin{array}{c}\text { Duration of } \\
\text { the disease } \\
\text { (months) }\end{array}$ & $\begin{array}{c}\text { Duration of } \\
\text { corticosteroid } \\
\text { therapy } \\
\text { (months) }\end{array}$ & $\begin{array}{c}\text { Signs of } \\
\text { bleeding } \\
\text { before VCR } \\
\text { therapy* }\end{array}$ & $\begin{array}{c}\text { Platelet } \\
\text { count } \\
\text { before VCR } \\
\text { therapy } \\
\left(\times 10^{9} / 1\right)\end{array}$ & $\begin{array}{c}\text { Platelet } \\
\text { count } \\
\text { after VCR } \\
\text { therapy } \\
\left(\times 10^{\circ} / 1\right)\end{array}$ & $\begin{array}{l}\text { Signs of } \\
\text { bleeding } \\
\text { after VCR } \\
\text { therapy }\end{array}$ \\
\hline 1 & 41 & $\mathbf{F}$ & 48 & 24 & ++ & 30 & 160 & - \\
\hline 2 & 17 & $\mathbf{F}$ & 15 & 3 & ++ & 20 & 160 & - \\
\hline 3 & 48 & $\mathrm{~F}$ & 60 & 10 & ++ & 20 & 92 & - \\
\hline 4 & 30 & $\mathbf{F}$ & 28 & 10 & ++ & 30 & 70 & - \\
\hline 5 & 34 & F & 60 & 24 & $++t$ & 15 & 45 & - \\
\hline 6 & 17 & $F$ & 48 & 36 & $++t$ & 10 & 10 & $+t+$ \\
\hline 7 & 17 & $\mathbf{M}$ & 60 & 24 & + & 10 & 10 & - \\
\hline 8 & 41 & $\mathbf{F}$ & 154 & 24 & + & 10 & 12 & + \\
\hline
\end{tabular}

* Criteria for the semi quantitative estimation of purpura: - absence of bleeding; + bleeding to little traumatism; ++ spontaneous bleeding; +++ spontaneous skin and mucose bleeding.

criteria included: severe thrombocytopenia $(<50 \times$ $10^{9} / 1$ ) without leucopenia or splenomegaly; a cellular and active bone marrow with a normal or increased number of megakaryocytes; presence of signs and symptoms ascribable only to blood loss or focal bleeding; absence of a detectable relationship of purpura with drugs or other aetiological agents; negative antinuclear-antibody and L.E.cell tests (Bouroncle and Doan, 1969; Laros and Penner, 1971; Ahn et al., 1974).

Vincristine administration. A dose of $1 \mathrm{mg}$ of vincristine sulphate was given i.v. each week up to complete a total dose of $4 \mathrm{mg}$. Subsequently, the treatment was discontinued. One patient received only $1 \mathrm{mg}$ because of the normalization of the platelet count and disappearance of the purpura after the first dose.

Haematological studies. The platelet count was performed by phase-microscopy, initially on a weekly basis and later the interval was lengthened as the individual response to therapy became apparent. The normal platelet values in the authors' laboratory are from 150 to $400 \times 10^{9} / 1$.

Criteria of response. Criteria for response are defined as follows: (1) Complete remission (normal platelet count and disappearance of purpura); (2) Partial remission (rise of the platelet count up to $50-100 \times 10^{9} / 1$ or up to 3 -fold the initial count, with persistent or transient cessation of purpura); (3) Failure (absence of response).

\section{Results}

Two patients achieved a complete remission, one of them with a single dose of vincristine. Both are in remission 5 and 20 months after therapy. Three other patients had a partial remission, lasting 5 months in one case, and followed by a relapse after one and 4 months in the remaining 2 cases, although one of them has stopped bleeding. There was a failure in 3 patients. Nevertheless, one of them has stopped bleeding after vincristine therapy even without a detectable rise in the platelet count. The responses are shown in Figs 1, 2 and 3.

The mean duration in months of the disease and of corticosteroid-therapy were $42 \cdot 2$ (range 15-60) and 14.2 (range 3-24) in the patients who achieved a remission (complete or partial) and 87.3 (range 48-154) and 28 (24-36) in the cases of failure. Statistical comparison of these data was not significant.

Side effects (numbness of fingers and constipation $\$ \vec{\varphi}$ were observed in only one patient.

\section{Discussion}

ITP appears to be an autoimmune disorder, as suggested by the demonstration of IgG-type antiplatelet antibodies (Karpatkin et al., 1972), that render the platelets susceptible to destruction by the macrophages (Harrington et al., 1972; Ahn et al., 1978). Although this seems the main mechanism, an additional role of cell-mediated immunity has not been excluded (Harrington et al., 1972). The benefit of splenectomy would result not only from an increase of the platelet life span by removal of the major mass of macrophages, but from the destruction of the main source of IgG-type antibodies (Ahn et al., 1978; Rosse, 1978). Corticosteroids, by reducing antibody production, may be useful. Corticosteroids and/or splenectomy result in acceptable clinical control in 70 to $90 \%$ of all patients (Laros and Penner, 1971; Ahn et al., 1974).

Based on the fact that ITP is generally caused by $N$ antibodies, immunosuppresive agents may be useful $N$ in refractory ITP with serious disease, as well as in patients unsuitable for surgery and for corticosteroids (Finch et al., 1974). Cyclophosphamide and azathioprine have been for many years the first choice agents (Bouroncle and Doan, 1966, 1969; Laros and Penner, 1971; Verlin, Laros and Penner, 1972; Finch et al., 1974; Rosse, 1978). However, they have the disadvantage of the long 
duration of treatment required, and their myelotoxicity (Bouroncle and Doan, 1969; Ahn et al., 1978; Rosse, 1978). Other agents such as methotrexate, chlorambucil, 6-mercaptopurine, actinomycin $\mathrm{C}, \mathrm{L}$-asparaginase and thioguanine, have been used generally with disappointing results (Rozman et al., 1969; Finch et al., 1974; Ahn et al., 1978).

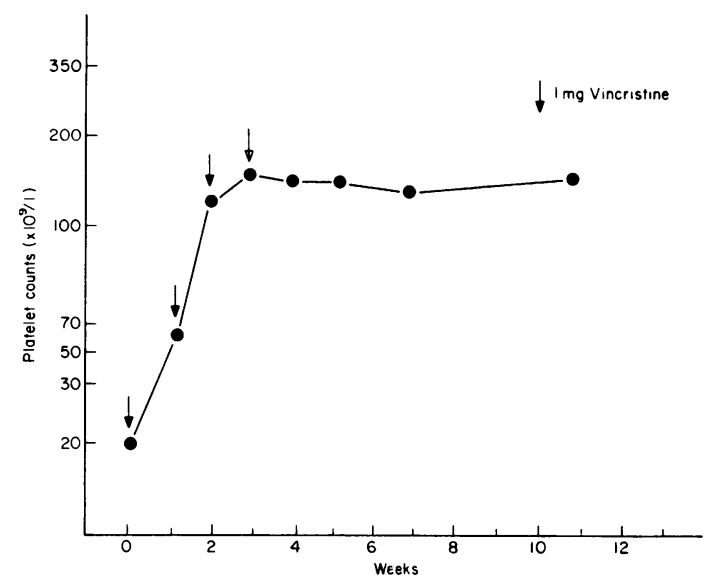

FIG. 1. Complete remission after vincristine therapy.

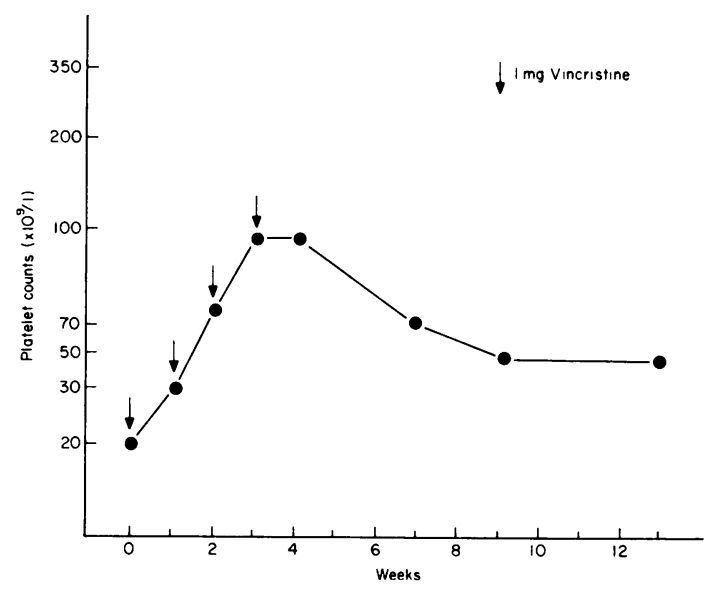

Fig. 2. Partial remission after vincristine therapy.

In the last few years, the Vinca alkaloids have been increasingly used in refractory ITP. They are cytostatic for the macrophages. The Vinca alkaloids bind to tubulin, the structural protein of microtubules. As platelets are very rich in microtubules, they are avid in uptake of Vinca alkaloids (Ahn et al., 1978). The agent, carried by the platelets,

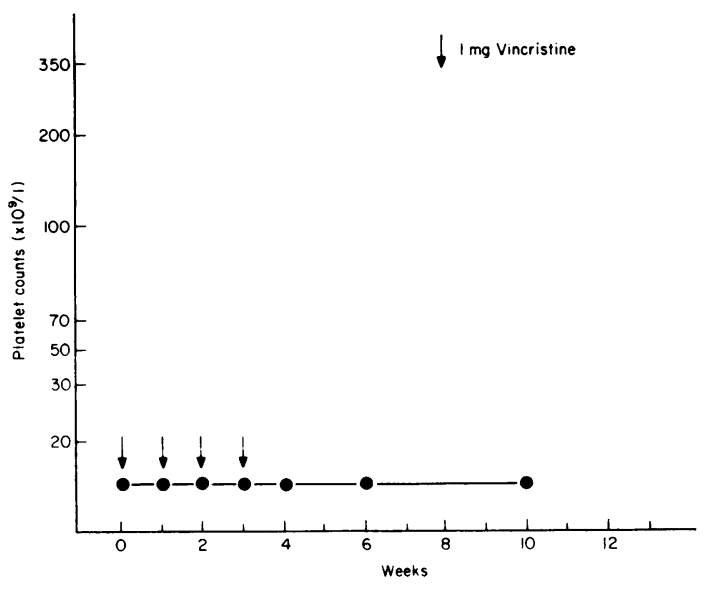

FIG. 3. Failure to vincristine therapy.

would go into the macrophages, leading to their dysfunction or death (Ahn et al., 1978; Wautier et al., 1978). Consequently, a 'medical' splenectomy would be produced, decreasing the platelet clearance as well as the anti-platelet antibody production (Harrington et al., 1972; Ahn et al., 1978; Rosse, 1978). Nevertheless, Vinca alkaloids have also been useful in splenectomized patients (Harrington et al., 1972; Ahn et al., 1974). Moreover, thrombocytosis is frequently observed in patients treated with Vinca alkaloids for oncological disorders (Carbone et al., 1969; Robertson et al., 1972; Ahn et al., 1978; Retsas, Newton and Westbury, 1978). Both observations suggest that, besides the cytostatic effect, the alkaloids have a second thrombocytopoietic effect (Sultan et al., 1971). Experimental studies in laboratory animals, in which thrombocytosis followed the administration of the Vinca alkaloids (Robertson et al., 1972), may give support for the latter hypothesis. Thrombocytosis could be due to a rise in the platelet production (Robertson et al., 1972), perhaps by an increase in megakaryocyte endomitosis (Ahn et al., 1974). Thus, 2 independent effects of the drug would act in ITP. This double action (cytostatic and thrombocytopoietic) would be an advantage as compared to other immunosuppressive agents.

Among the Vinca alkaloids, vincristine appears to offer the best results with less side effects (Robertson and McCarthy, 1969). Because of this, their indication in refractory ITP is increasing (Harrington et al., 1972; Ahn et al., 1974; Burton et al., 1976; Tangun and Atamer, 1977; Rosse, 1978; Zeile, 1978). The frequency of successful (complete or partial) responses is about $60 \%$ (Ahn et al., 1978). It has been pointed out that vincristine could be more effective in splenectomized 
patients (Harrington et al., 1972; Ahn et al., 1974; Ries, 1976). However, when non-splenectomized corticosteroid-refractory patients, as those included in the present series, are considered (Harrington et al., 1972; Ahn et al., 1974; Burton et al., 1976; Tangun and Atamer, 1977; Zeile, 1978) the level of successful responses is very similar. The authors cannot find any explanation for the fact that some patients with severe disease stopped bleeding after vincristine administration, despite a lack of improvement in the platelet level.

Other factors that have been implicated in the response to immunosuppressive agents are the duration of the disease and of corticosteroid therapy (Verlin et al., 1972; Finch et al., 1974). Although the response to immunosuppressive therapy has been found to be inversely related to the duration of the disease (Finch et al., 1974), this is not so for most series of ITP treated with vincristine (Sultan et al., 1971; Ahn et al., 1974). In the present patients there was a trend favouring an influence of the duration of the disease in the responsiveness to vincristine therapy but this was not significant.

The appearance of toxic side effects is the main factor limiting prolonged vincristine administration (Ahn et al., 1974; Burton et al., 1976). Vincristineneurotoxicity is related to the total dose and duration of therapy (Sandler, Tobin and Henderson, 1969). In previous studies, dosage has been of a 2-mg bolus or one $\mathrm{mg} / \mathrm{m}^{2}$, given weekly or every 10 days up to a total of 3 to 6 doses or to the appearance of response or side effects (Harrington et al., 1972; Ahn et al., 1974; Burton et al., 1976; Wautier et al., 1978; Zeile, 1978). Besides the transient effect of vincristine, the frequent appearance of toxicity at those dosages would be the reason for limiting its use to special situations: a prompt solution of a serious bleeding, an improvement of the platelet levels in order to allow a splenectomy or as an interim measure until a slow-acting immunosuppressive agent becomes effective (Burton et al., 1976; Tangun and Atamer, 1977). In the present patients, side effects were very infrequent, while the level of successful responses was similar to those achieved at higher dosages.

As it may be inferred from these results, a lowdose regime of vincristine may be as useful as a higher dose regime, having the advantage of its lesser toxicity. Thus, low-dose vincristine may be the therapy of choice in the management of refractory ITP.

\section{References}

AhN, Y.S., Harrington, W.J., Seelman, R.C. \& Eytel, C.S. (1974) Vincristine therapy of idiopathic and secondary thrombocytopenias. New England Journal of Medicine, $291,376$.
Ahn, Y.S., Byrnes, J.J., Harrington, W.J., Cayer, M. L., SMith, D.S., Brunskill, D.E. \& Pall, L.M. (1978) The treatment of idiopathic thrombocytopenia with

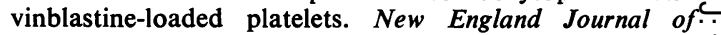
Medicine, 298, 1101.

BouronCle, B.A. \& DoAN, C.A. (1966) Refractory idiopathic thrombocytopenia purpura treated with azathio-O prine. New England Journal of Medicine, 275, 630.

BouronCle, B.A. \& DoAN, C.A. (1969) Treatment of $\frac{\bar{\sigma}}{\bar{\omega}}$ refractory idiopathic thrombocytopenic purpura. Journal $\vec{\nabla}$ of the American Medical Association, 207, 2048.

Burton, I.E., Roberts, B.E., Child, J.A., Montgomery, ص D.A. \& RAPER, C.G.L. (1976) Responses to vincristine ${ }^{\infty}$ in refractory idiopathic thrombocytopenic purpura. $\vec{\circ}$ British Medical Journal, $2,918$.

Carbone, P.P., Bono, V., Frel, E. \& Brindley, C.O. (1969) $\vec{\omega}$ Clinical studies with vincristine. Blood, 21, 640.

Finch, S.C., Castro, O., Cooper, M., Covey, W., Erichson, R. \& MCPhedran, P. (1974) Immunosuppressive therapy of chronic idiopathic thrombocytopenic purpura. American Journal of Medicine, 56, 4.

Harrington, W.J., AhN, Y.S. \& Gilibert, J.J. (1972) Vincristine therapy of idiopathic thrombocytopenia. Blood, 40, 971.

Karpatkin, S., Strick, N. \& Suskind, G.W. (1972) Detection of splenic antiplatelet antibody synthesis in $\vec{a}$ idiopathic autoimmune thrombocytopenic purpura (ITP). 윽 British Journal of Haematology, 23, 167.

LARos, R.K. \& Penner, J.A. (1971) 'Refractory' thrombocytopenic purpura treated successfully with cyclophosphamide. Journal of the American Medical Association, $\overrightarrow{0}$ 215, 445.

Massimo, L., Genova, R., Marchi, A., Masera, G, Massolo, I. \& MoRI, P.G. (1977) More on vincristipe in treatment of ITP in children. New England Journal $q f{ }^{\infty}$ Medicine, 297, 397.

Retsas, S., Newton, K.A. \& Westbury, G. (1978) Vinên alkaloids and platelets. New England Journal of Medicine, 299, 310.

RIES, C.A. (1976) Vincristine for treatment of refractory autoimmune thrombocytopenia. New England Journal of $\frac{\mathrm{Q}}{\mathbb{Q}}$ Medicine, 295, 1136.

Robertson, J.H. \& MCCARThy, G.M. (1969) Periwinkle $\overrightarrow{\vec{F}}$ alkaloids and the platelet-count. Lancet, ii, 353.

RoberTSON, J.H., CROZIER, G.H. \& WOODEND, B.E. (1972) Vincristine-induced thrombocytosis studied with ${ }^{75}$ Se selenomethionine. Acta haematologica, 47, 356.

Rosse, W.F. (1978) Selective chemotherapy of macrophages in the treatment of idiopathic thrombocytopenic purpura. 3 New England Journal of Medicine, 298, 1139.

Rozman, C., Rios, A. \& Hernandez-Nieto, L. (1969) Púrpura trombocitopénica idiopática. Remisión con 6-mercaptopurina. Medicina Clínica. Barcelona, 52, 215.

SANDler, S.G., Tobin, W. \& Henderson, E.S. (1969) Vincristine-induced neuropathy. Neurology, 19, 367.

Sultan, Y., Delobel, J., Jeanneau, C. \& Caen, J.P. (1971) 의 Effect of periwinkle alkaloids in idiopathic thrombocytopenic purpura. Lancet, i, 496.

TANGUN, Y. \& ATAMER, T. (1977) More on vincristine in $\tilde{N}$ treatment of ITP. New England Journal of Medicine, 5 297, 894.

Verlin, M., Laros Jr., R.K. \& Penner, J.A. (1972) Re- 응 fractory thrombocytopenic purpura treated successfully $\omega$ with cyclophosphamide. Blood, 40, 971.

Wautier, J.L., Boizard, B., Rendu, F. \& CAEN, J.P. (1978) Vinca alkaloids and platelets. New England Journal $\frac{\bar{D}}{\bar{C}}$ of Medicine, 299, 310.

ZEILE, G. (1978) Vincristin-therapy of chronic refractory idiopathic thrombocytopenic purpura. Blut, 36, 217. 